\title{
Contribuição do rio Cocó e riacho Maceió na sedimentação da plataforma interna de Fortaleza-CE
}

\author{
Contribution of the Cocó river and Maceió creek in the sedimentation of the internal \\ plataform of Fortaleza-CE
}

\author{
LIMA FILHO ${ }^{1}$, R. P..; CASTELO BRANCO ${ }^{2}$, M. P. N.; PINHEIRO ${ }^{3}$, L. S.
}

regimario@alu.ufc.br

\begin{abstract}
Resumo
A plataforma continental interna de Fortaleza nas últimas décadas sofre com constantes alterações morfológicas e sedimentológicas devido a forte influência antrópica e por fatores naturais. O principal objetivo deste trabalho é correlacionar às características sedimentológicas e os teores de carbonato de cálcio e matéria orgânica de amostras coletadas em dois ambientes relativamente próximos, mas com padrão sedimentológico e morfológico bastante distintos. As análises com os parâmetros propostos no trabalho mostraram que o ambiente ao largo do riacho Maceió com uma predominância de areia muito fina e silte, e do rio Cocó areia grossa e muito grossa. Em geral, os teores de carbonato de cálcio e matéria orgânica foram maiores na área do riacho Maceió, mostrando ser um ambiente de baixa intensidade dinâmica. Em contrapartida, a área do rio Cocó, por ser uma região aberta à incidência de ondas, apresenta uma maior atividade hidrodinâmica (deriva litorânea), que favorece a dispersão de materiais, resultando, portanto, no não acúmulo de matéria orgânica e carbonato de cálcio.
\end{abstract}

Palavras-chave: Plataforma continental; análise granulométrica, teores de matéria orgânica e carbonato de cálcio.

\begin{abstract}
The continental shelf of Fortaleza in the last decades suffers with constant morphological and sedimentological alterations due to strong antropic influence and natural factors. The main objective of this work is to correlate sedimentological characteristics, calcium carbonate and organic matter contents of samples collected in two relatively close environments, but with quite different sedimentological and morphological patterns. The analyzes with the parameters proposed in the work showed the environment off the Maceió creek with a predominance of very fine sand and silt, and the coarse and very coarse sand of the Cocó river. In general, calcium carbonate and organic matter contents were higher in the Maceió stream area, showing a low dynamic intensity environment, and in contrast, the Cocó River area, being a region open to the incidence of waves, presents a greater hydrodynamic activity (coastal drift), favors the dispersion of materials resulting in the non-accumulation of organic matter and calcium carbonate.
\end{abstract}

Keywords: Continental shelf; granulometric analysis; organic matter and calcium carbonate.

\section{INTRODUÇÃO}

As áreas costeiras das grandes metrópoles, em função do incremento populacional, vêm sendo alvo de intenso uso e ocupação territorial. Esses processos ocupacionais muitas vezes imprimem no ambiente físico um aspecto degradacional, que podem influenciar nas formas de fundo e nos processos de sedimentação da plataforma continental interna adjacente (Lacerda et al. 2008).

A região Metropolitana de Fortaleza desde a implantação das obras portuárias vem sofrendo impactos ambientais, refletidas por intensos processos erosivos ao longo da linha de costa. Esses efeitos foram minimizados pela implantação de espigões/molhes, cujo objetivo principal foi de 
amortecer as ações impactantes dos processos oceanográficos sobre a linha de costa (Morais 1972; 1981).

Inúmeros trabalhos foram desenvolvidos na área visando a caracterização hidrodinâmica, evolucional e ambiental da região, sendo os mais relevantes os desenvolvidos por Morais (1972; 1981); Pitombeira (1976); Maia (1998) e Ximenes Neto (2015; 2018).

A faixa de praia situada no trecho litorâneo a leste da região portuária caracteriza-se por livre ação dos processos oceanográficos, como: ondas e correntes de deriva litorânea. Correspondendo, portanto, a uma região marcada por alta atividade dinâmica, e é nesse trecho que principal rio que corta a capital cearense deságua no oceano Atlântico (Silva et al, 2009).

O rio Cocó tem sua nascente nos maciços cristalinos da serra da Aratanha (CE) e drena a região Metropolitana de Fortaleza. Em seu médio e baixo curso o rio escoa sobre os Tabuleiros Costeiros e a Planície Litorânea, ambientes marcados por extensas áreas planas que são submetidas às inundações periódicas, e que nos dias atuais encontram-se ocupados pela malha urbana de Fortaleza (Leal, 2014).

De modo geral, a apropriação deste espaço é marcada por ocupações de populações socialmente menos favorecidas, que por ocasião de chuvas mais intensas, são submetidas às adversidades desse ambiente. Contando ainda com uma carência total de saneamento básico, o que ocasiona como conseqüência, um maior lançamento de fontes poluidoras no curso fluvial. Esse cenário confronta-se com os processos atuais de expansão urbana, marcada por uma parcela mais abastada da cidade (Zanella et al., 2013).

Em contraste, a área do riacho Maceió, setor oeste-central da orla da cidade de Fortaleza, devido sua localização em áreas abrigadas, em função da presença do molhe do complexo industrial portuário, sofre menor ação das correntes costeiras (Morais, 1981).

O riacho Maceió corre integralmente na cidade de Fortaleza, tendo sua origem no bairro do Papicu e deságüe na orla da cidade, em um parque urbano do mesmo nome no bairro do Mucuripe. Atualmente, em função da acessibilidade da metrópole, encontra-se escoando sobre valas cobertas (Leal, 2014).

A fonte da sedimentação terrígena mapeada na plataforma continental interna da orla de Fortaleza corresponde ao fluxo do rio Cocó e riacho Maceió (Morais (1972; 1981); Pitombeira (1976); Maia (1998); Silva et al., 2009).

Dessa maneira, o objetivo principal do presente estudo foi de realizar uma correlação entre as características sedimentológicas, teores de carbonato de cálcio e matéria orgânica das amostras coletadas na plataforma continental interna (até 20 metros de profundidade) situada defronte a 
desembocadura do rio Cocó e ao largo da bacia de sedimentação do porto de Fortaleza, deságue do riacho Maceió.

\section{METODOLOGIA}

A grade amostral foi definida de acordo com os objetivos do Projeto CIRCUNPLACE (Importância da Circulação para o Transporte e Destino de Contaminantes Orgânicos na Plataforma Continental do Ceará) (Figura 1). Na região da foz do rio Cocó foram coletadas 16 amostras e na região da foz do riacho Maceió foram coletadas 15 amostras (Tabela 1).

As coletas foram realizadas entre os dias 09 e 14 de abril de 2018, em uma embarcação de porte médio, com auxílio de equipamentos de GPS para navegação. As coletas de sedimento do substrato marinho na plataforma interna foram realizadas por meio de um amostrador pontual de fundo do tipo van veen.

Em campo, as amostras foram acondicionadas em sacos plásticos, etiquetadas e conduzidas para o laboratório de Oceanografia Geológica - LABOMAR/UFC, para serem analisadas de acordo com a metodologia de Suguio (1973).

Em laboratório, as amostras foram inicialmente secas na estufa em temperatura de $60^{\circ} \mathrm{C}$, por tempo suficiente para a completa secagem do sedimento. O procedimento teve como etapas seguintes a pesagem de 100 gramas e o peneiramento úmido, com objetivo de separar as frações arenosas e finas (silte + argila).

A fração de diâmetro superior a $0,062 \mu$ (fração areia) foi analisada granulometricamente pelo processo de peneiramento mecânico, que consiste em uma bateria de peneiras de malhas variáveis acoplada a um agitador mecânico (rotap).

As frações de silte e argila $(\varnothing<0,062 \mu)$ foram analisadas pela método da pipetagem (Suguio, 1973).

A determinação do percentual carbonático $\left(\mathrm{CaCO}_{3}\right)$ nas amostras foi realizada pelo método do calcímetro de Bernard modificado, que mede a concentração de $\mathrm{CaCO}_{3}$ dos sedimentos através da captação e medição de gás carbônico utilizando um calcímetro volumétrico. Esse processo é resultante da reação do ácido clorídrico (HCL) com o carbonato de cálcio $\left(\mathrm{CaCO}_{3}\right)$ existente na amostra do sedimento, resultando na liberação de dióxido de carbono $\left(\mathrm{CO}_{2}\right)$. O volume de $\mathrm{CO}_{2}$ liberado é proporcional à concentração de carbonato de cálcio no sedimento.

A determinação do percentual de matéria orgânica (M.O.) nas amostras foi realizada pelo método gravimétrico, que consiste na combustão de $2 \mathrm{~g}$ do sedimento previamente seco em mufla a $450^{\circ} \mathrm{C}$, por 2 horas. 
Os parâmetros estatísticos para a determinação da média do diâmetro dos grãos foram feitos com o auxílio do software Anased 5.0. (Lima et. al. 2001). As amostras peneiradas foram classificadas pela média, na concepção de areia muito grossa, areia grossa, areia média, areia fina, areia muito fina, e algumas amostras foram classificadas como silte grosso e silte fino.

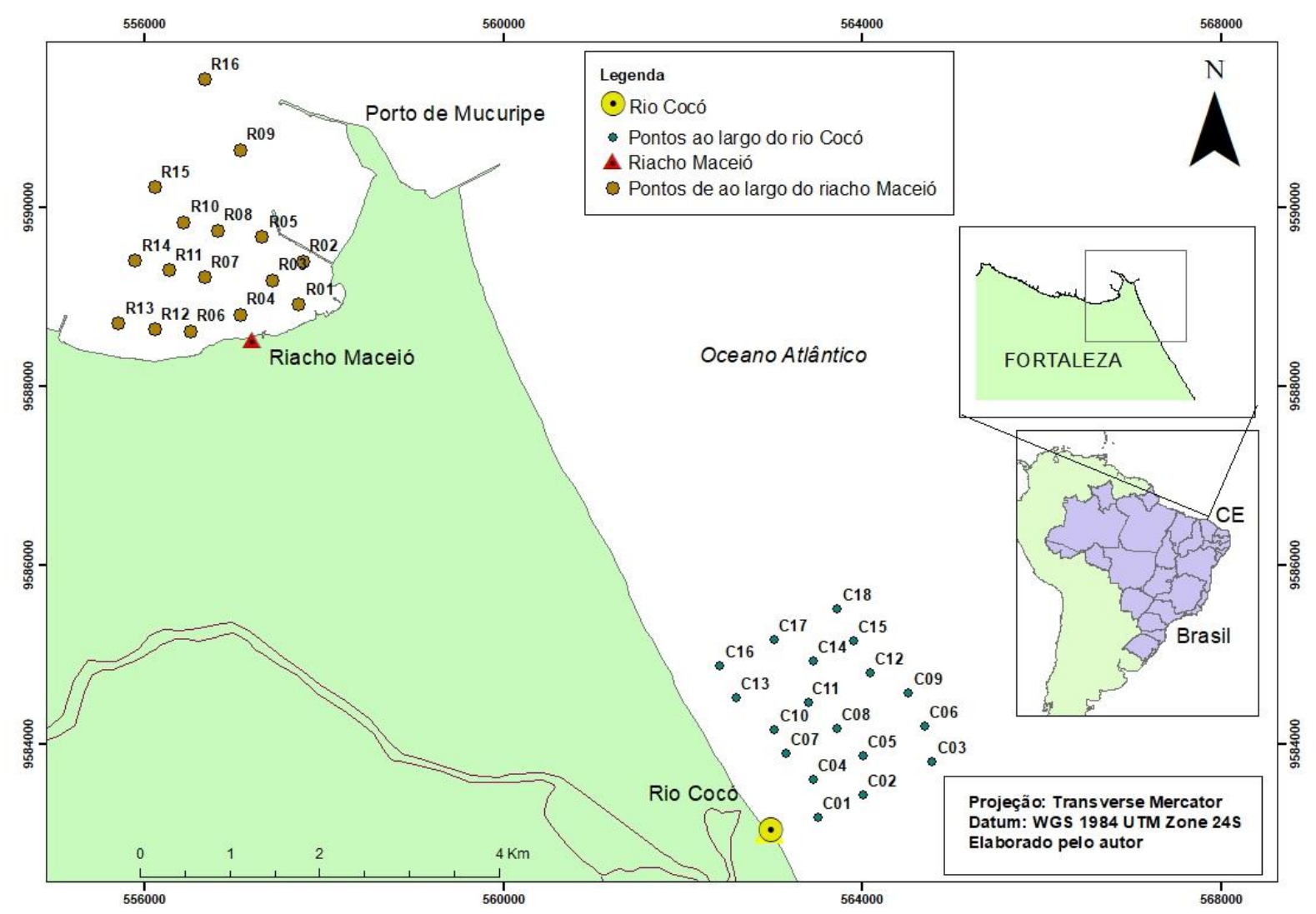

Figura 1 - Mapa de localização das áreas e das malhas amostrais. Fonte: Autoria própria.

Tabela 1: Coordenadas dos pontos e profundidades nas desembocaduras do rio Cocó e riacho Maceió (Datum SAD-69). Fonte: Autoria própria.

\begin{tabular}{|c|c|c|c|c|c|c|c|}
\hline $\begin{array}{c}\text { RIO } \\
\text { COCó }\end{array}$ & LONGITUDE & LATITUDE & $\begin{array}{l}\text { PROFUNDIDADE } \\
(\mathrm{m})\end{array}$ & $\begin{array}{l}\text { RIACHO } \\
\text { MACEIÓ }\end{array}$ & LONGITUDE & LATITUDE & $\begin{array}{c}\text { PROFUNDIDADE } \\
(\mathrm{m})\end{array}$ \\
\hline C01 & 563508.6128 & 9583185 & 10.8 & R01 & 557716.2399 & 9588918.309 & 3.6 \\
\hline $\mathrm{C02}$ & 564016.0125 & 9583433 & 13.7 & R02 & 557766.6243 & 9589396.96 & 4.1 \\
\hline $\mathrm{CO3}$ & 564788.0659 & 9583810 & 16.7 & R03 & 557422.3312 & 9589187.025 & 4.2 \\
\hline C04 & 563456.439 & 9583605 & 12.8 & R04 & 557061.2433 & 9588800.745 & 4.3 \\
\hline C05 & 564009.1974 & 9583875 & 14.8 & R05 & 557304.7677 & 9589665.676 & 7.8 \\
\hline C06 & 564698.3314 & 9584211 & 16.5 & R06 & 556507.0154 & 9588616.002 & 4.38 \\
\hline C07 & 564522.7973 & 9584571 & 12.7 & R07 & 556666.5658 & 9589220.615 & 5.78 \\
\hline
\end{tabular}




\begin{tabular}{|l|c|c|c|c|c|c|c|}
\hline C08 & 563724.2642 & 9584181 & 14.2 & $R 08$ & 556809.3215 & 9589741.253 & 6.7 \\
\hline C09 & 563157.5445 & 9583904 & 16.3 & R09 & 557063.7437 & 9590643.443 & 14.2 \\
\hline C11 & 563401.1362 & 9584468 & 13.4 & R10 & 556431.5699 & 9589836.413 & 7 \\
\hline C12 & 564089.7957 & 9584805 & 15.4 & R11 & 556270.1638 & 9589298.393 & 6.1 \\
\hline C13 & 563906.7099 & 9585160 & 9.7 & R12 & 556108.7578 & 9588639.318 & 4.16 \\
\hline C15 & 562600.844 & 9584519 & 14.5 & R13 & 555705.2426 & 9588706.571 & 4.8 \\
\hline C16 & 562420.5303 & 9584876 & 8.1 & R14 & 555893.5497 & 9589405.997 & 5.7 \\
\hline C17 & 563017.8462 & 9585171 & 12.1 & R15 & 556108.7578 & 9590226.478 & 7.8 \\
\hline C18 & 563729.0924 & 9585519 & 13.2 & R16 & 556665.282 & 9591425.48 & 13.5 \\
\hline
\end{tabular}

\section{RESULTADOS E DISCUSSÃO}

Os resultados obtidos nas análises sedimentológicas das amostras coletadas nas plataformas internas adjacentes a foz do rio Cocó e a foz do riacho Maceió foram interpretados e, visando melhor visualização, foram apresentados em forma de gráficos e mapas.

3.1 Fácies sedimentares das plataformas internas na foz do rio Cocó e na foz do riacho Maceió

As variações faciológicas mapeadas nas duas áreas (rio Cocó e riacho Maceió) estão representadas na Figura 2.

A interpretação dos dados aponta que a maior parte da área na plataforma continental interna adjacente ao rio Cocó é composta de sedimentos mais grossos. Os sedimentos de textura mais fina aparecem em menor quantidade na área.

Os sedimentos mapeados na plataforma continental interna na área situada defronte a foz do riacho Maceió foram caracterizados predominantemente por uma sedimentação de grãos de pequenos diâmetros, representados pelas areias muito fina dos pontos R07 ao R15 com média de areia muito fina de 35 a 91\%, com exceção do ponto R09, que apresenta 77\% de silte. Os pontos R01 ao R06 apresentaram média de 74 a 99\% de silte e argila.

O predomínio desses sedimentos finos na bacia portuária pode ser associado às atividades rotineiras de acesso ao porto (dragagens), assim como, por ser uma área abrigada pelas estruturas (molhes/espigões) construídas na implantação do Porto do Mucuripe, ocasionando, portanto, uma bacia portuária abrigada das ações oceanográficas (MORAIS, 1972; SOARES, 2012; Ximenes Neto, 2018).

Dessa maneira, os resultados das análises granulométricas nas duas áreas levam a associar a sedimentação na foz do rio Cocó à ação direta das ondas e correntes, enquanto o predomínio de uma 
sedimentação fina na área de deságue do riacho Maceió (bacia portuária) a baixa energia atuante no meio. Corroborando, portanto, com a afirmação de Komar (1998), que diz que a topografia de fundo, a energia de dissipação das ondas e a intensidade local de turbulência espelham-se no tamanho do sedimento.

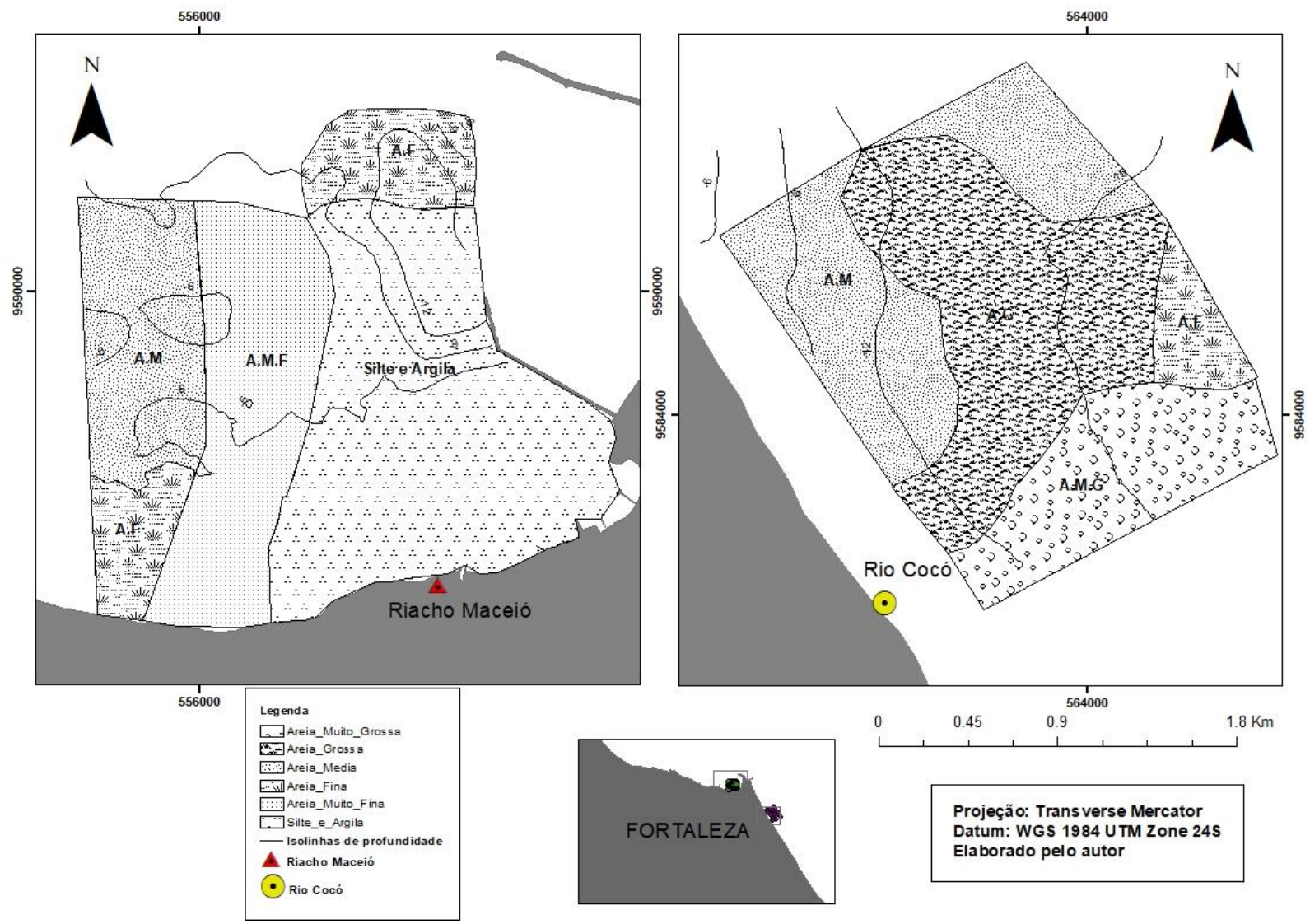

Figura 2 - Mapas de fácies das plataformas internas do rio Cocó e do riacho Maceió. Fonte: Autoria própria.

\subsection{Parâmetros da plataforma interna na foz do rio Cocó}

Os teores de carbonato de cálcio $\left(\mathrm{CaCO}_{3}\right)$ na área adjacente ao rio Cocó apresentaram uma variação de $9 \%$ a $29 \%$. Foi observado que os sedimentos de maior teor carbonático estão distribuídos nos pontos de maior profundidade da malha, como é o caso dos pontos C06 (29\%) e C12 (20\%), localizados numa profundidade superior a 14 metros (Tabela 1).

Os pontos localizados em profundidades menores, em torno de 9 metros, apresentaram um teor de carbonato menor, como é o caso dos pontos C16 (9\%) e C01 (12\%).

De acordo com a classificação de Larsonneur (1977), todas as 16 amostras apresentaram uma porcentagem menor que 30\%, sendo, portanto, classificadas como Litoclásticas.

Os valores de matéria orgânica (M.O.) apresentaram teores variando entre 0,2 a 1\% (Figura 3). Os dados apresentados na Tabela 2 permitiram verificar a inexistência de um padrão de 
correlação entre os resultados (teores de carbonato de cálcio, matéria orgânica e classificação granulométrica). Esse fato provavelmente resulta da particularidade de ser um ambiente altamente influenciado pelas ações envolvidas na dinâmica costeira (ondas, marés, correntes de deriva), capazes de ocasionar uma mistura de grãos.

Tabela 2 - Dados da região ao largo do rio Cocó. Fonte: Autoria própria.

\begin{tabular}{lccc}
\hline Ponto & $\mathbf{C a C O}_{\mathbf{3}}(\%)$ & $\mathbf{M . O . ( \% )}$ & $\begin{array}{c}\text { CLASSIFICAÇÃO } \\
\text { GRANULOMÉTRICA }\end{array}$ \\
\hline C01 & 12.63 & 0.29 & AREIA MUITO GROSSA \\
C02 & 9.29 & Sem dado & AREIA MUITO GROSSA \\
C03 & 19.47 & 0.51 & AREIA MUITO GROSSA \\
C04 & 17.42 & 0.43 & AREIA GROSSA \\
C05 & 19.29 & 0.89 & AREIA MUITO GROSSA \\
C06 & 29.33 & 0.28 & AREIA FINA \\
C07 & 19.47 & 0.48 & AREIA MÉDIA \\
C08 & 13.91 & 0.36 & AREIA GROSSA \\
C09 & 14.34 & 0.47 & AREIA FINA \\
C10 & 21.79 & Sem dado & Sem dado \\
C11 & 14.38 & 0.1 & AREIA GROSSA \\
C12 & 20.36 & 0.64 & AREIA GROSSA \\
C13 & 6.83 & Sem dado & AREIA MÉDIA \\
C14 & 17.52 & Sem dado & Sem dado \\
C15 & 15.38 & 1.15 & AREIA MÉDIA \\
C16 & 8.39 & 0.59 & AREIA MÉDIA \\
C17 & 17.06 & 0.64 & AREIA GROSSA \\
C18 & 15.66 & 0.15 & AREIA MÉDIA \\
\hline
\end{tabular}

3.3 Parâmetros da plataforma interna na foz do riacho Maceió

Os teores de carbonato de cálcio $\left(\mathrm{CaCO}_{3}\right)$ na área adjacente ao riacho Maceió variaram de 0,4\%. a 48\%. Os sedimentos com maior teor carbonático estão distribuídos próximos a foz do riacho, como por exemplo, os pontos R04 (49\%), R01 (46\%) e R03 (41\%). Enquanto que os sedimentos com menor teor carbonático estão localizados em pontos mais distantes da desembocadura do riacho (R14 (4\%) e R13 (6\%)).

De acordo com a classificação de Larsonneur (1977), as 15 amostras de sedimentos coletadas no substrato marinho situado na foz do riacho Maceió foram classificadas como Litobioclásticos (R01, R03, R04, R06, R07, R09 e R12), com teores de $\mathrm{CaCO}_{3}$ variando de 30 a $50 \%$. Os demais pontos foram classificados como Litoclásticos, com teores de $\mathrm{CaCO}_{3}$ menores que $30 \%$. 
Os teores de matéria orgânica (M.O.) variaram de $0,1 \%$ a $8 \%$. Os mais altos valores de matéria orgânica foram verificados nos pontos R03 (8\%), R15 (7,5\%) e R09 (7,4\%), enquanto os menores valores foram registrados nos pontos R13 (0,4\%), R14 (0,4\%) e R11 (0,1\%).

O enriquecimento de matéria orgânica pode estar associado a proximidade das amostras ao canal de acesso do porto, onde existe uma predominância de sedimentos finos, assim como a áreas abrigadas pelas obras de engenharia do sistema portuário (molhe/espigão), e a sua localização em relação a linha de costa e profundidade local.

Os dados apresentados na Tabela 3 mostram a distribuição dos teores de carbonato de cálcio, matéria orgânica e a classificação granulométrica das amostras coletadas no domínio do deságue do riacho Maceió. A interpretação apontou haver uma tendência de associação das amostras com grãos mais finos serem retentores dos mais elevados percentuais de carbonato de cálcio e dos menores percentuais de matéria orgânica.

Tabela 3 - Dados da região ao largo do Riacho Maceió. Fonte: Autoria própria.

\begin{tabular}{lccc}
\hline Ponto & $\mathbf{C a C O}_{\mathbf{3}}(\%)$ & $\mathbf{M . O}$ (\%) & $\begin{array}{c}\text { CLASSIFICAÇÃO } \\
\text { GRANULOMÉTRICA }\end{array}$ \\
\hline R01 & 47.6 & 3.89 & SILTE FINO \\
\hline R02 & 19.14 & 5.4 & AREIA MUITO FINA \\
\hline R03 & 41.38 & 7.95 & SILTE FINO \\
\hline R04 & 49.61 & 1.03 & SILTE MÉDIO \\
\hline R05 & 28.4 & 4.01 & SILTE GROSSO \\
\hline R06 & 47.04 & 3.43 & SILTE GROSSO \\
\hline R07 & 38.81 & 2.79 & SILTE GROSSO \\
\hline R08 & 26.72 & 2.2 & AREIA MUITO FINA \\
\hline R09 & 34.18 & 7.31 & SILTE GROSSO \\
\hline R10 & 15.15 & 0.79 & AREIA MUITO FINA \\
\hline R11 & 18.37 & 0.02 & AREIA MUITO FINA \\
\hline R12 & 34.43 & 2.35 & AREIA MUITO FINA \\
\hline R13 & 6.03 & 0.34 & AREIA FINA \\
\hline R14 & 3.58 & 0.34 & AREIA MÉDIA \\
\hline R15 & 13.49 & 7.49 & AREIA MUITO FINA \\
\hline R16 & 12.23 & 0.73 & AREIA FINA \\
\hline
\end{tabular}

\section{CONSIDERAÇÕES FINAIS}

Os resultados encontrados nas análises laboratoriais das amostras coletadas no presente estudo sinalizam uma nítida diferença entre as características sedimentológicas das duas áreas deságues do rio Cocó e do riacho Maceió, apesar de estarem relativamente próximas.

A sedimentação presente na plataforma interna adjacente a foz do rio Cocó é marcada exclusividade por areias (muito grossas, grossas, médias e finas) (Figura 2). 
Por outro lado, a sedimentação presente na plataforma interna adjacente a foz do riacho Maceió caracteriza-se por sedimentos de granulometria finas, marcados por depósitos de areias muito finas, finas e médias (R03, R04, R05, R06, R10, R11, R12, R13, R14 e R15) e de siltes grossos e finos (R01, R02, R07, R08, R09) (Figura 2 e Tabela 3).

De maneira geral, essas diferenças sedimentológicas verificadas nas áreas de deságue do rio Cocó e riacho Maceió ocorrem em função da morfologia da linha de costa e da ação das atuantes oceanográficas.

As condições faciológicas registradas na plataforma interna adjacente a foz do rio Cocó marca-se por fácies exclusivamente arenosa (muito grossas, grossas, médias e finas), cuja fonte corresponde, provavelmente, a processos intempéricos das rochas pré-cambrianas e Fanerozóicas (Paleogeno/Neogeno - Tabuleiro pré-litorâneo (Formação Barreiras) e Quaternário - Planície Costeira) a qual o curso fluvial está encravado. Assim como a exposição do aporte sedimentar a ação das agentes oceanográficos fortemente atuantes na bacia deposicional.

A princípio pode-se associar uma sedimentação mais fina na plataforma interna adjacente a foz do riacho Maceió a natureza geológica dos terrenos pela qual o riacho percorre (Tabuleiro prélitorâneo - Formação Barreiras e Planície litorânea), a capacidade do transporte do riacho e a menor exposição da área deposicional a ação das ondas e correntes, em função da presença das estruturas antrópicas resultantes da implantação do Porto do Mucuripe (molhes/espigões), que conseqüentemente induzem a um ambiente de águas calmas e de baixa energia.

Dessa maneira, a diferença faciológica das duas áreas deposicionais está nitidamente relacionada a fatores físicos (intemperismo) nas rochas onde os cursos fluviais estão encravados e a intensidade das ações oceanográficas atuantes na bacia sedimentar (plataforma continental interna).

Os teores de carbonato de cálcio nas duas áreas variaram entre 9 a 29\% (rio Cocó) e 0,4 a 48\% (riacho Maceió). Sendo, portanto, possível observar que as amostras coletadas na plataforma interna adjacente a foz do riacho Maceió, em relação as coletadas no rio Cocó, são mais enriquecidas em teores de carbonato de cálcio. Fato esse, provavelmente associado ao maior desgaste das frações carbonáticas por ação dos agentes oceanográficos presentes na plataforma do litoral leste.

Os registros obtidos nas amostras do rio Cocó revelaram uma correspondência com a profundidade. As amostras mais rasas, até 9 metros, assumiram menores percentuais, e as mais profundas, 14 metros, valores maiores (C06 e C12).

As amostras coletadas na plataforma interna do riacho Maceió não mostraram nenhum padrão de distribuição, entretanto, pode-se verificar que as amostras coletas mais próximas a foz do riacho (R01 e R03) assumiram maiores percentagens. 
A determinação de matéria orgânica em ambas as áreas pesquisadas mostra valores variando de 0,2 a 1\% de M.O. na área do rio Cocó e 0,1 a 8\% de M.O. na área do riacho Maceió. Os valores registrados nas duas áreas apontam comportamento semelhante a distribuição de carbonato de cálcio, maiores teores nas amostras coletadas na plataforma interna adjacente a foz do riacho Maceió. Esse enriquecimento de matéria orgânica pode ser correlacionado a uma maior deposição de sedimentos finas (silte e argila) na bacia portuária, assim como a baixa energia atuante no ambiente.

\section{REFERÊNCIAS}

KOMAR, P. D. Beach processes and sedimentation. Englewood Cliffs: Prentice-Hall. 1998.

LACERDA, L. D.; MOLISANI, M. M.; SENA, D. \& MAIA, L. P. Estimating the importance of natural and anthropogenic sources on $\mathrm{N}$ and $\mathrm{P}$ emission to estuaries along the Ceará State Coast NE Brazil. Environmental Monitoring and Assessment, v. 141, p. 149-164, 2008

LARSONNEUR, C. La cartographie des dépots meubles sur le plateau continental français: mèthode mise au point et utilisée en Manche. J.Rech.Oceanogra., 2:34-39, 1977.

LEAL, J. R. L. V. Mudança de curso do rio Cocó no paleolítico superior. Revista do Instituto do Ceará. 2014. 183-217p.

LIMA, S. F.; SILVA FILHO, W. F.; FREIRE, G. S. S.; MAIA, L.P.; DANTAS, R. P.; MONTEIRO, L. H. U. . ANASED 5.0i, Programa de Análise, Classificação e Arquivamento de Parâmetros Sedimentológicos. 2001.

MAIA, L. P. Procesos y balance sedimentário a ló largo de Fortaleza (NE-Brasil): implicaciones para uma gestión adecuada de La zona litoral. Tese (Doutorado em ciências Del mar). Facultat de Geologia, Universitat de Barcelona. 1998. 281p.

MORAIS, J. O. Processo de assoreamento do Porto de Mucuripe. Arquivo Ciências do Mar, v.12, p. 139-149, 1972.

J. O. Evolução sedimentológica da Enseada do Mucuripe. Arquivo de Ciências do Mar, v. 21,p. 19-46, 1981

PAULA, D. P. Análise dos riscos de erosão costeira no litoral de Fortaleza em função da vulnerabilidade aos processos geogênicos e antropogênicos. (Doutorado em Ciências do Mar). Universidade do Algarve. Portugal. 335p.

PITOMBEIRA, E. S. Deformação das ondas por difração no molhe do Porto do Mucuripe (Fortaleza - Ceará - Brazil). Fortaleza: Arquivo de Ciências do Mar, v.16(1), p.55-58, 1976.

ROCHA, D. A.; FROTA, H. B.; MEIRELES, A. J. A. (2008). Ecossistema manguezal do rio Cocó e o licenciamento ambiental do Iguatemi empresarial, em Fortaleza/CE. In: Congresso Latino 
Americano de direitos humanos e pluralismo jurídico. Campus Trindade, Universidade Federal de Santa Catarina. Florianópolis.

SILVA, A. C., PINHEIRO, L. S., MAIA, L. P., MORAIS, J. O. (2009). Estudo hidrodinâmico e bacteriológico associado às fontes Pontuais de Poluição ao longo do litoral de Fortaleza. Revista Brasileira de Recursos Hídricos 14, 83-90.

SOARES, R. C. Evolução e Caracterização do Banco Sedimentar de Fortaleza, Ceará, Brasil. Dissertação de Mestrado. Universidade Estadual do Ceará-UECE. Fortaleza-CE, 2012. 116p.

SUGUIO, K. Introdução à sedimentologia. São Paulo, Edgard Blucher, 317p., 1973

XIMENES NETO, A. R. Evolução da paisagem submarina do litoral norte de Fortaleza - CE. Monografia (Trabalho de Conclusão de Curso em Geografia). Universidade Estadual do Ceará, 2015.78p.

XIMENES NETO, A. R.; MORAIS, J.O; PINHEIRO, L. S. Distribuição das formas de fundo e padrões sedimentares no porto do Mucuripe, Fortaleza-Ceará. Revista Brasileira de Geomorfologia (Online), São Paulo, v.19, n. 2, p.321-339, 2018.

ZANELLA, M. A.; OLÍMPIO, J. L.; LUSTOSA COSTA, M. C.; DANTAS, W. C. Vulnerabilidade Socioambiental do Baixo Curso da Bacia Hidrográfica do Rio Cocó, Fortaleza-Ceará. Sociedade \& Natureza, vol. 25, num. 2, mayo-agosto, 2013, PP.317-331. Universidade Federal de Uberlândia. Uberlândia, Minas Gerais, Brasil.

\section{AGRADECIMENTOS}

A FUNCAP (Fundação Cearense de Apoio ao Desenvolvimento Científico e Tecnológico) pelo apoio financeiro e pelo fomento de bolsas aos participantes do projeto CIRCUMPLACE (Importância da Circulação para o Transporte e Destino de Contaminantes Orgânicos na Plataforma Continental do Ceará). E ao Laboratório de Oceanografia Geológica (LOG) do Instituto de Ciências do Mar (LABOMAR) da Universidade Federal do Ceará (UFC), onde as análises foram realizadas.

Recebido em: 12/08/2019

Aceito para publicação em: 01/11/2019 